\title{
A Controlled Trial of Rivaroxaban after Transcatheter Aortic-Valve Replacement
}

\author{
G.D. Dangas, J.G.P. Tijssen, J. Wöhrle, L. Søndergaard, M. Gilard, H. Möllmann, \\ R.R. Makkar, H.C. Herrmann, G. Giustino, S. Baldus, O. De Backer, \\ A.H.C. Guimarães, L. Gullestad, A. Kini, D. von Lewinski, M. Mack, R. Moreno, \\ U. Schäfer, J. Seeger, D. Tchétché, K. Thomitzek, M. Valgimigli, P. Vranckx, \\ R.C. Welsh, P. Wildgoose, A.A. Volkl, A. Zazula, R.G.M. van Amsterdam, \\ R. Mehran, and S. Windecker, for the GALILEO Investigators*
}

ABSTRACT

The authors' full names, academic degrees, and affiliations are listed in the Appendix. Address reprint requests to $\mathrm{Dr}$. Windecker at Inselspital, Bern University Hospital, University of Bern, Freiburgstr. 18, Bern 3010, Switzerland, or at stephan .windecker@insel.ch.

*A complete list of investigators in the GALILEO trial is provided in the Supplementary Appendix, available at NEJM.org.

This article was published on November 16, 2019, at NEJM.org.

N Engl J Med 2020;382:120-9. DOI: 10.1056/NEJMoa1911425

Copyright (C) 2019 Massachusetts Medical Society.

\section{BACKGROUND}

Whether the direct factor Xa inhibitor rivaroxaban can prevent thromboembolic events after transcatheter aortic-valve replacement (TAVR) is unclear.

\section{METHODS}

We randomly assigned 1644 patients without an established indication for oral anticoagulation after successful TAVR to receive rivaroxaban at a dose of $10 \mathrm{mg}$ daily (with aspirin at a dose of 75 to $100 \mathrm{mg}$ daily for the first 3 months) (rivaroxaban group) or aspirin at a dose of 75 to $100 \mathrm{mg}$ daily (with clopidogrel at a dose of $75 \mathrm{mg}$ daily for the first 3 months) (antiplatelet group). The primary efficacy outcome was the composite of death or thromboembolic events. The primary safety outcome was major, disabling, or life-threatening bleeding. The trial was terminated prematurely by the data and safety monitoring board because of safety concerns.

\section{RESULTS}

After a median of 17 months, death or a first thromboembolic event (intention-to-treat analysis) had occurred in 105 patients in the rivaroxaban group and in 78 patients in the antiplatelet group (incidence rates, 9.8 and 7.2 per 100 person-years, respectively; hazard ratio with rivaroxaban, 1.35; 95\% confidence interval [CI], 1.01 to 1.81; $\mathrm{P}=0.04)$. Major, disabling, or life-threatening bleeding (intention-to-treat analysis) had occurred in 46 and 31 patients, respectively (4.3 and 2.8 per 100 person-years; hazard ratio, $1.50 ; 95 \% \mathrm{CI}, 0.95$ to $2.37 ; \mathrm{P}=0.08$ ). A total of 64 deaths occurred in the rivaroxaban group and 38 in the antiplatelet group (5.8 and 3.4 per 100 personyears, respectively; hazard ratio, 1.69; $95 \% \mathrm{CI}, 1.13$ to 2.53 ).

\section{CONCLUSIONS}

In patients without an established indication for oral anticoagulation after successful TAVR, a treatment strategy including rivaroxaban at a dose of $10 \mathrm{mg}$ daily was associated with a higher risk of death or thromboembolic complications and a higher risk of bleeding than an antiplatelet-based strategy. (Funded by Bayer and Janssen Pharmaceuticals; GALILEO ClinicalTrials.gov number, NCT02556203.) 
T RANSCATHETER AORTIC-VALVE REPLACEment (TAVR) is indicated in symptomatic severe aortic stenosis. ${ }^{1-7}$ Thromboembolic complications (stroke, systemic embolism, valve thrombosis, and venous thromboembolism) have been observed after TAVR. Observational data suggest that subclinical leaflet thrombosis may occur with bioprosthetic valves and that this phenomenon may be associated with an increased risk of cerebrovascular events and prevented or reversed by anticoagulation. ${ }^{8-13}$ Current practice guidelines recommend the use of dual antiplatelet therapy early after TAVR, ${ }^{14,15}$ although the recommendation is based mainly on expert consensus.

Rivaroxaban directly inhibits factor Xa and has been shown to reduce the risk of thromboembolism in different clinical settings. ${ }^{16-18}$ The 10-mg daily dose has been approved for the prevention of venous thromboembolism in several countries. However, there is a dearth of evidence for routine use of anticoagulation after TAVR for the prevention of thromboembolic events. In addition, patients undergoing TAVR are typically elderly, frail, and at increased risk for both ischemic and bleeding complications. In GALILEO (Global Study Comparing a Rivaroxaban-based Antithrombotic Strategy to an Antiplatelet-based Strategy after Transcatheter Aortic Valve Replacement to Optimize Clinical Outcomes), we investigated the role of a treatment strategy including anticoagulation with rivaroxaban at a dose of $10 \mathrm{mg}$ daily as compared with an antiplatelet strategy in patients without established indications for anticoagulation after successful TAVR.

\section{METHODS}

\section{TRIAL DESIGN AND OVERSIGHT}

GALILEO was a randomized, open-label, eventdriven, multicenter trial. ${ }^{19}$ The trial was conducted in compliance with the International Conference on Harmonisation and the Declaration of Helsinki. The protocol (available with the full text of this article at NEJM.org) was approved by the ethics committees and corresponding health authorities for all participating sites. All the patients provided written informed consent to participate.

The trial was supported by the sponsors, Bayer and Janssen Pharmaceuticals. The sponsors and the academic investigators designed and supervised the trial, which was executed with the as- sistance of the two clinical research organizations, Cardialysis (Rotterdam, the Netherlands) and the Center for Interventional Cardiovascular Research and Clinical Trials (Mount Sinai Hospital, New York). The executive committee included members of the academic leadership and the sponsors. Data analyses were conducted by DATAN (Havixbeck, Germany). An independent data and safety monitoring board provided oversight by periodically reviewing all reported serious adverse events. The first, second, and last authors wrote the first draft of the manuscript and made the decision to submit it for publication. All the authors reviewed and critiqued subsequent drafts and vouch for the accuracy and completeness of the data and for the fidelity of the trial to the protocol. (Additional information about trial organization is provided in the Supplementary Appendix, available at NEJM.org.)

\section{PATIENT SELECTION AND RANDOMIZATION}

Men and women 18 years of age or older were eligible for participation in the trial if they had undergone successful TAVR for treatment of aortic-valve stenosis. Successful TAVR was defined as correct positioning of any single approved transcatheter bioprosthetic aortic valve into the proper anatomical location with the intended valve performance and without periprocedural complications. $^{20}$ Key exclusion criteria were any established indication for long-term anticoagulation and any absolute indication for dual antiplatelet therapy. (See Supplementary Appendix text and Table S1 for screening procedures and a complete list of the inclusion and exclusion criteria.) After written informed consent had been obtained, eligible patients were randomly assigned (in a 1:1 ratio) through an interactive Web-response system to either the rivaroxaban group or the antiplatelet group 1 to 7 days after TAVR and before hospital discharge.

\section{TRIAL TREATMENT AND FOLLOW-UP}

The anticoagulant (experimental) group was assigned to receive rivaroxaban at a dose of $10 \mathrm{mg}$ daily plus aspirin at a dose of 75 to $100 \mathrm{mg}$ daily for 3 months, followed by rivaroxaban monotherapy (10 mg daily). The antiplatelet (control) group was assigned to receive aspirin at a dose of 75 to $100 \mathrm{mg}$ daily plus clopidogrel at a dose of $75 \mathrm{mg}$ daily for 3 months (patients who had not previ- 
ously received clopidogrel were recommended to receive a single loading dose of $\geq 300 \mathrm{mg}$ ), followed by aspirin monotherapy (75 to $100 \mathrm{mg}$ daily).

Patients in the rivaroxaban group in whom atrial fibrillation developed were to receive rivaroxaban at a dose of $20 \mathrm{mg}$ once daily (or $15 \mathrm{mg}$ for those with an estimated glomerular filtration rate of 30 to $50 \mathrm{ml}$ per minute per $1.73 \mathrm{~m}^{2}$ of body-surface area). In the antiplatelet group, patients in whom new-onset atrial fibrillation developed were to receive vitamin $\mathrm{K}$ antagonists (targeting an international normalized ratio of 2 to 3$)$ to replace clopidogrel within 3 months after randomization or to replace aspirin thereafter.

Rivaroxaban was centrally supplied to the sites as trial medication. Clopidogrel, aspirin, and vitamin $\mathrm{K}$ antagonists were supplied according to local practice. Patients were followed at 1 , 3 , and 6 months and every 6 months thereafter. (Details of the follow-up procedures and recommendations for concomitant medications are provided in the Supplementary Appendix.)

\section{OUTCOME MEASURES}

The primary efficacy outcome was the composite of death from any cause or thromboembolic events, including any stroke, myocardial infarction, symptomatic valve thrombosis, systemic embolism (not involving the central nervous system), deep-vein thrombosis, or pulmonary embolism. The primary safety outcome was the composite of life-threatening, disabling, or major bleeding. The secondary efficacy outcome was defined as the primary efficacy outcome with death from cardiovascular causes replacing death from any cause. The net-benefit outcome included all components of the primary efficacy and primary safety outcomes. All the above outcomes and their components were adjudicated in a blinded manner by an independent clinical-events committee according to Valve Academic Research Consortium definitions. ${ }^{20}$ (See Table S2 for detailed definitions.)

\section{STATISTICAL ANALYSIS}

The primary hypothesis was that the rivaroxaban group would be superior to the antiplatelet group with respect to the time from randomized treatment assignment to the first occurrence of any component of the primary efficacy outcome. The trial was event-driven; we estimated that 440 pri- mary efficacy outcome events would provide the trial with $80 \%$ power to detect a $20 \%$ lower relative risk in the rivaroxaban group than in the antiplatelet group. (Details on the power calculation and statistical methods are provided in the Supplementary Appendix.)

No formal interim analyses for efficacy or futility were planned. After review by the data and safety monitoring board on August 7, 2018, immediate termination of the trial was recommended because of safety concerns. The trial leadership and the sponsors accepted this recommendation for trial termination on August 13, 2018 (efficacy cutoff date). Because the trial was terminated early, only 183 patients reached the primary efficacy outcome ( $42 \%$ of the planned 440 ).

The statistical analysis plan originally specified that the primary efficacy outcome was to be analyzed for noninferiority (with a noninferiority margin for the upper boundary of the hazard ratio of 1.20) in the on-treatment data set; a hierarchical testing strategy specified that no tests for superiority would be performed if noninferiority was not shown. However, it was subsequently decided to present conventional twosided $\mathrm{P}$ values to test for the between-group difference for both the primary efficacy outcome and the primary safety outcome; the approach described below and in the Results section is based on that decision.

The main analyses were performed according to the intention-to-treat principle. For time-toevent analyses, hazard ratios and $95 \%$ confidence intervals were generated with Cox proportionalhazards models. The confidence intervals were not adjusted for multiple comparisons, and therefore inferences drawn from these intervals may not be reproducible. Kaplan-Meier curves were used to show the incidence of outcomes over time. The proportionality assumption for the primary efficacy and safety outcomes was not violated.

For the primary efficacy outcome and the primary safety outcome, conventional two-sided log-rank P values were calculated. Prespecified subgroup analyses followed Cox proportionalhazards methods. To describe early and late risks of outcome events, we performed landmark analyses on a post hoc basis with the landmark time point set at 90 days after randomization.

For the on-treatment analyses, trial outcomes were included if they occurred before premature permanent discontinuation of the 
assigned trial regimen. The time of premature permanent discontinuation was defined as 2 days after the last ingestion of a trial medication. On-treatment Cox regression analyses were performed by imposing additional censoring at the day of premature permanent discontinuation of the trial regimen.

\section{RESULTS}

\section{TRIAL POPULATION}

From December 2015 through May 2018, a total of 1644 patients underwent randomization after successful TAVR in 136 centers in 16 countries (Table S3); 826 patients were randomly assigned to the rivaroxaban group and 818 to the antiplatelet group. The median time from TAVR to randomization was 2.0 days (range, 0 to 8 ). Baseline characteristics are shown in Table 1 . The mean $( \pm$ SD) age was $80.6 \pm 6.6$ years; $49.5 \%$ of the patients were female.

\section{ADHERENCE AND FOLLOW-UP}

Follow-up was complete for $96.8 \%$ of the patients, and vital status was available for $98.0 \%$ (Fig. 1); the median trial duration was 17 months (interquartile range, 13 to 21). Throughout the trial period, 307 patients in the rivaroxaban group prematurely discontinued the trial regimen, as compared with 194 in the antiplatelet group (Tables S4 and S5 and Fig. S1). In the rivaroxaban group, the median exposure to rivaroxaban was 428 days (interquartile range, 171 to 581), and the median exposure to aspirin was 90 days (interquartile range, 84 to 94). In the antiplatelet group, the median exposure to aspirin was 474 days (interquartile range, 298 to 603), and the median exposure to clopidogrel was 90 days (interquartile range, 85 to 93). New-onset atrial fibrillation developed in $11.0 \%$ of the trial population (Table S6).

\section{PRIMARY AND SECONDARY EFFICACY OUTCOMES}

In the intention-to-treat analysis, death or first thromboembolic event (the primary efficacy outcome) occurred in 105 patients in the rivaroxaban group and in 78 patients in the antiplatelet group (incidence rates, 9.8 and 7.2 per 100 person-years, respectively; hazard ratio with rivaroxaban, 1.35; $95 \%$ confidence interval $[\mathrm{CI}], 1.01$ to $1.81 ; \mathrm{P}=0.04$ ) (Fig. 2A and Table 2). This effect was consistent across prespecified subgroups (Fig. S2).
Death from cardiovascular causes or any thromboembolic event (the key secondary outcome) occurred in 83 patients in the rivaroxaban group and in 68 patients in the antiplatelet group (incidence rates, 7.8 and 6.3 per 100 person-years, respectively; hazard ratio, 1.22; 95\% CI, 0.89 to 1.69). Symptomatic valve thrombosis occurred in 3 patients in the rivaroxaban group and in 7 patients in the antiplatelet group (incidence rates, 0.3 and 0.6 per 100 person-years, respectively; hazard ratio, 0.43 ; $95 \% \mathrm{CI}, 0.11$ to 1.66 ). Rates of stroke and myocardial infarction did not differ significantly between the two groups.

A total of 64 deaths occurred in the rivaroxaban group, and 38 occurred in the antiplatelet group (incidence rates, 5.8 and 3.4 per 100 personyears, respectively; hazard ratio for rivaroxaban, 1.69; 95\% CI, 1.13 to 2.53) (Fig. 2B and Table 2). Noncardiovascular mortality rates were 2.6 and 1.0 per 100 person-years, respectively (hazard ratio, 2.67; 95\% CI, 1.33 to 5.35). Cardiovascular mortality rates were 3.2 and 2.4 per 100 personyears, respectively (hazard ratio, 1.30; 95\% CI, 0.79 to 2.14). Adjudicated causes of death are presented in Tables S7 through S9.

\section{PRIMARY SAFETY OUTCOME}

In the intention-to-treat analysis, life-threatening, disabling, or major bleeding (the primary safety outcome) occurred in 46 patients in the rivaroxaban group and 31 patients in the antiplatelet group (incidence rates, 4.3 and 2.8 per 100 person-years, respectively; hazard ratio with rivaroxaban, $1.50 ; 95 \% \mathrm{CI}, 0.95$ to $2.37 ; \mathrm{P}=0.08$ ) (Fig. 2C). There was no significant betweengroup difference in the rate of life-threatening or disabling bleeding (1.6 and 1.5 per 100 personyears, respectively; hazard ratio, 1.06; 95\% CI, 0.55 to 2.06). Bleeding rates according to other prespecified definitions occurred more frequently in the rivaroxaban group than in the antiplatelet group (Table 2). Subgroup analyses for the primary safety outcome are shown in Figure S3.

\section{LANDMARK AND ON-TREATMENT ANALYSES}

Landmark analyses for the primary efficacy and safety outcomes and for death from any cause are shown in Figures S4 through S6. In the ontreatment analyses, a primary efficacy outcome event occurred in 68 patients during use of rivaroxaban and in 63 patients during use of antiplatelet therapy (incidence rates, 8.1 and 6.6 per 
100 person-years, respectively; hazard ratio with rivaroxaban, $1.21 ; 95 \% \mathrm{CI}, 0.86$ to 1.70 ). A primary safety outcome event occurred in 39 and 28 patients, respectively (incidence rates, 4.6 and
2.9 per 100 person-years; hazard ratio, 1.53 ; $95 \%$ CI, 0.94 to 2.49; $\mathrm{P}=0.08$ ). There were 26 and 24 deaths during treatment, respectively (incidence rates, 3.0 and 2.5 per 100 person-years; hazard

\begin{tabular}{|c|c|c|}
\hline Characteristic & $\begin{array}{l}\text { Rivaroxaban Group } \\
\qquad(\mathrm{N}=826)\end{array}$ & $\begin{array}{l}\text { Antiplatelet Group } \\
\qquad(\mathrm{N}=818)\end{array}$ \\
\hline \multicolumn{3}{|l|}{ Demographic and clinical characteristics } \\
\hline Age - yr & $80.4 \pm 7.1$ & $80.8 \pm 6.0$ \\
\hline Male sex - no. (\%) & $426(51.6)$ & $405(49.5)$ \\
\hline Body-mass index & $28.1 \pm 5.5$ & $28.2 \pm 5.7$ \\
\hline Hypertension - no. (\%) & $720(87.2)$ & $697(85.2)$ \\
\hline Diabetes mellitus — no. (\%) & $236(28.6)$ & $235(28.7)$ \\
\hline EurOSCORE II & $4.1 \pm 3.9$ & $4.1 \pm 3.7$ \\
\hline \multicolumn{3}{|l|}{ EuroSCORE II risk category — no. (\%) $\ddagger$} \\
\hline High & $50(6.1)$ & $64(7.8)$ \\
\hline Intermediate & $139(16.8)$ & $140(17.1)$ \\
\hline Low & $636(77.0)$ & $613(74.9)$ \\
\hline Missing & $1(0.1)$ & $1(0.1)$ \\
\hline STS risk score $\mathbb{Z}$ & $4.0 \pm 3.2$ & $4.3 \pm 3.5$ \\
\hline \multicolumn{3}{|l|}{ STS risk category — no. (\%)』 } \\
\hline High & $65(7.9)$ & $74(9.0)$ \\
\hline Intermediate & $383(46.4)$ & $388(47.4)$ \\
\hline Low & $378(45.8)$ & $356(43.5)$ \\
\hline Congestive heart failure — no. (\%) & $394(47.7)$ & $380(46.5)$ \\
\hline NYHA class III or IV — no. (\%) & $250(30.3)$ & $222(27.1)$ \\
\hline Coronary artery disease — no. (\%) & $325(39.3)$ & $305(37.3)$ \\
\hline Previous stroke - no. (\%) & $51(6.2)$ & $35(4.3)$ \\
\hline Peripheral artery disease - no. (\%) & $83(10.0)$ & $82(10.0)$ \\
\hline Previous venous thromboembolism — no. (\%) & $18(2.2)$ & $15(1.8)$ \\
\hline Permanent pacemaker — no. (\%) & $80(9.7)$ & $80(9.8)$ \\
\hline Chronic obstructive pulmonary disease - no. (\%) & $110(13.3)$ & $88(10.8)$ \\
\hline Glomerular filtration rate $-\mathrm{ml} / \mathrm{min} / 1.73 \mathrm{~m}^{2}$ & $73.4 \pm 23.8$ & $73.2 \pm 23.2$ \\
\hline \multicolumn{3}{|l|}{ Procedural characteristics } \\
\hline \multicolumn{3}{|l|}{ Valve type - no. (\%) } \\
\hline Sapien XT, Edwards Lifesciences & $13(1.6)$ & $13(1.6)$ \\
\hline Sapien 3, Edwards Lifesciences & $385(46.6)$ & $346(42.3)$ \\
\hline CoreValve, Medtronic & $33(4.0)$ & $35(4.3)$ \\
\hline CoreValve Evolut R, Medtronic & $206(24.9)$ & $225(27.5)$ \\
\hline Lotus, Boston Scientific & $44(5.3)$ & 40 (4.9) \\
\hline Portico, St. Jude Medical & $44(5.3)$ & $40(4.9)$ \\
\hline Acurate Neo, Boston Scientific & $82(9.9)$ & 89 (10.9) \\
\hline Other & $19(2.3)$ & $30(3.7)$ \\
\hline Valve-in-valve - no. (\%) & $42(5.1)$ & $49(6.0)$ \\
\hline
\end{tabular}


Table 1. (Continued.)

$\begin{array}{lcc}\text { Characteristic } & \begin{array}{c}\text { Rivaroxaban Group } \\ (\mathbf{N}=826)\end{array} & \begin{array}{c}\text { Antiplatelet Group } \\ \text { (N=818) }\end{array} \\ \text { Post-TAVR echocardiographic characteristics } & 1.8 \pm 0.6 & 1.9 \pm 0.5 \\ \text { Aortic valve area - } \mathrm{cm}^{2} & 10.0 \pm 4.7 & 10.1 \pm 4.6 \\ \text { Mean aortic valve gradient - mm Hg } & 57.4 \pm 10.9 & 58.2 \pm 11.2 \\ \text { Left ventricular ejection fraction -\% } & & 168(20.5) \\ \text { Paravalvular aortic regurgitation - no. (\%) } & 157(19.0) & 10(1.2) \\ \quad \text { Mild } & 10(1.2) & \end{array}$

* Plus-minus values are means \pm SD. Percentages may not total 100 because of rounding. NYHA denotes New York Heart Association, and TAVR transcatheter aortic-valve replacement.

$\uparrow$ The body-mass index is the weight in kilograms divided by the square of the height in meters.

Scores on the European System for Cardiac Operative Risk Evaluation II (EuroSCORE II), which measure patient risk at the time of cardiovascular surgery, are calculated by means of logistic-regression equations. A score of greater than $10 \%$ indicates high risk, 5 to $10 \%$ intermediate risk, and less than $5 \%$ low risk.

$\int$ Society of Thoracic Surgeons (STS) risk scores, which measure patient risk at the time of cardiovascular surgery, are calculated by means of logistic-regression equations. A score of greater than $8 \%$ indicates high risk, 3 to $8 \%$ intermediate risk, and less than $3 \%$ low risk.

I Coronary artery disease was defined as previous myocardial infarction, percutaneous coronary intervention, or coronaryartery bypass grafting.

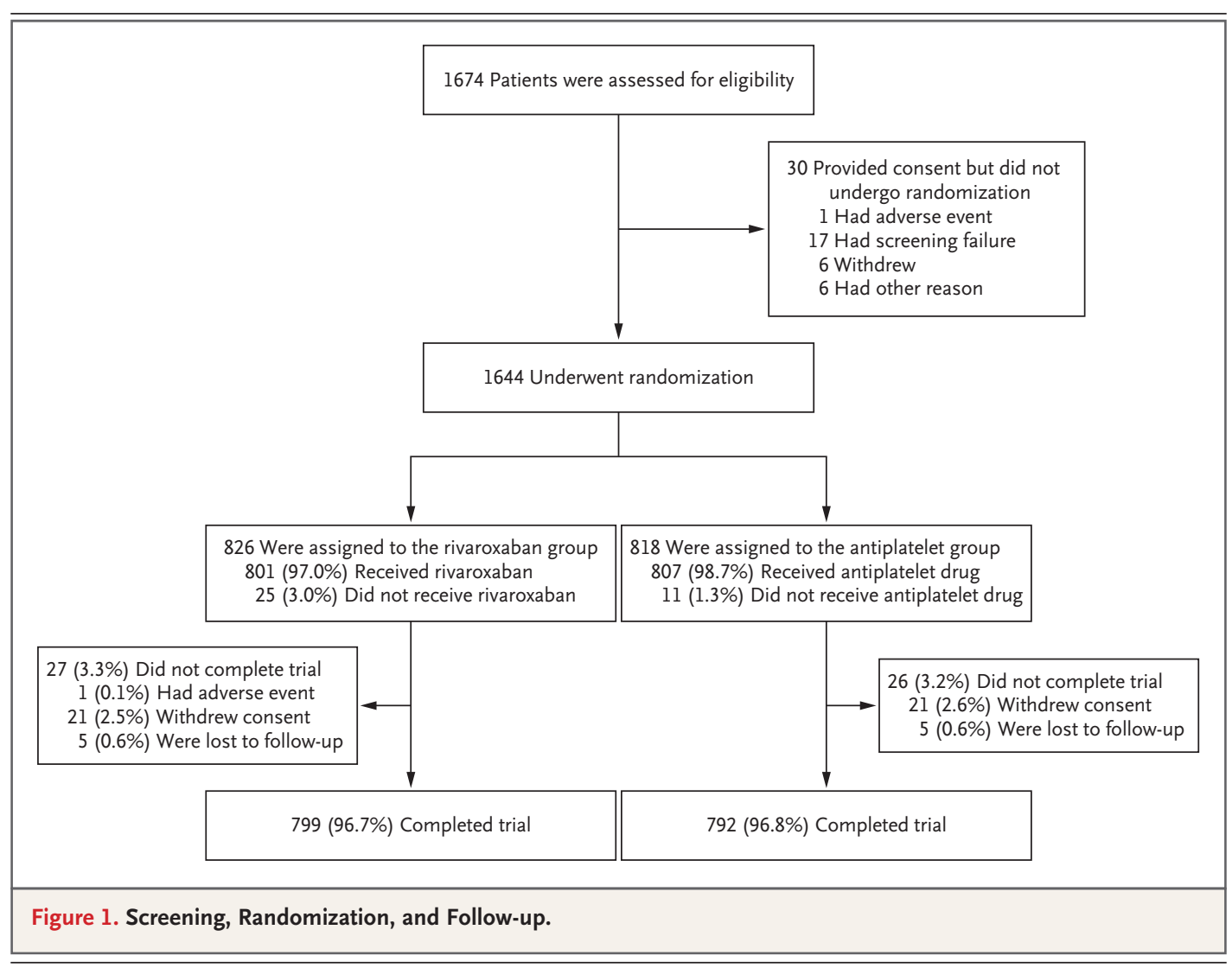




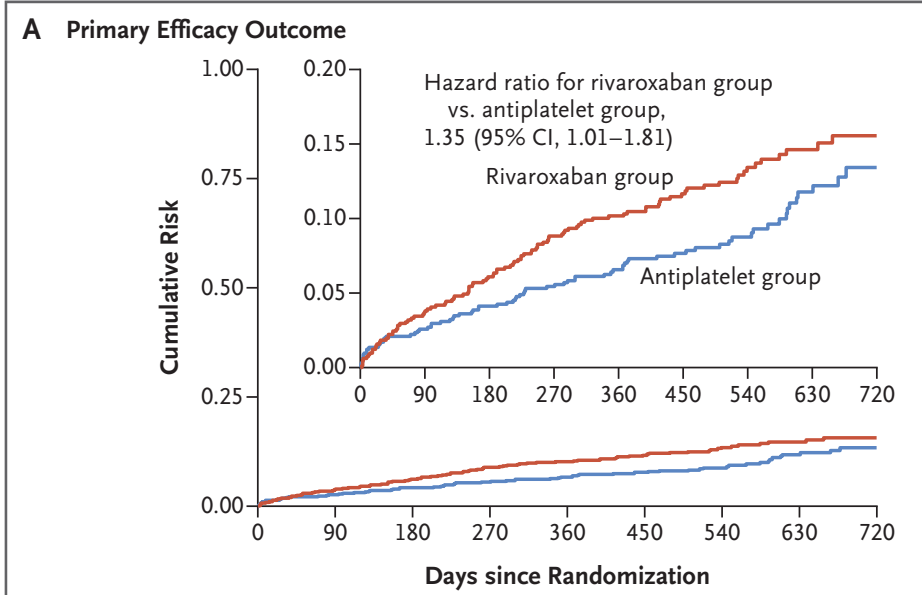

No. at Risk

$\begin{array}{llllllllll}\text { Rivaroxaban group } 826 & 777 & 738 & 687 & 604 & 476 & 335 & 206 & 90\end{array}$ $\begin{array}{llllllllll}\text { Antiplatelet group } & 818 & 779 & 740 & 699 & 622 & 496 & 339 & 211 & 93\end{array}$

B Death from Any Cause

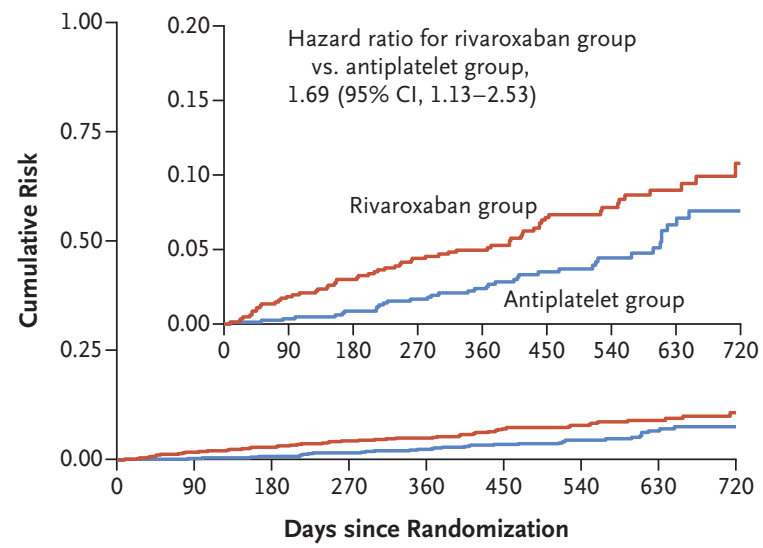

No. at Risk

$\begin{array}{llllllllll}\text { Rivaroxaban group } & 826 & 792 & 759 & 718 & 636 & 499 & 356 & 219 & 92\end{array}$

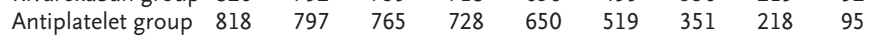

C Primary Safety Outcome

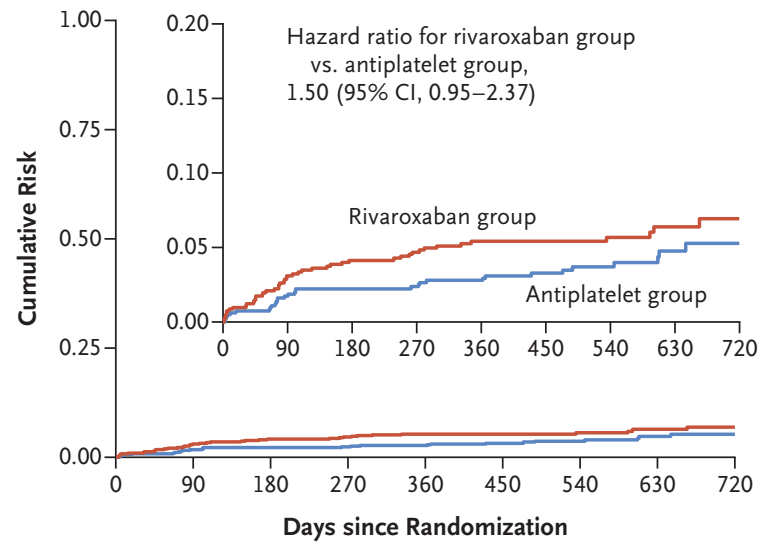

No. at Risk

$\begin{array}{llllllllll}\text { Rivaroxaban group } & 826 & 768 & 730 & 688 & 606 & 480 & 341 & 209 & 89\end{array}$ $\begin{array}{llllllllll}\text { Antiplatelet group } & 818 & 784 & 748 & 712 & 634 & 503 & 338 & 211 & 92\end{array}$
Figure 2. Cumulative Risk of the Primary Efficacy and Primary Safety Outcomes and Death from Any Cause (Intention-to-Treat Analysis).

Shown are time-to-event Kaplan-Meier curves for the primary efficacy outcome, death from any cause, and the primary safety outcome. The primary efficacy outcome was defined as the composite of death, stroke, myocardial infarction, symptomatic valve thrombosis, pulmonary embolism, deep-vein thrombosis, or systemic embolism. The primary safety outcome was defined as the composite of Valve Academic Research Consortium life-threatening, disabling, or major bleeding. The $95 \%$ confidence intervals (Cls) presented were not adjusted for multiple comparisons. Insets show the same data on an enlarged $y$ axis.

ratio, 1.23; 95\% CI, 0.71 to 2.15) (Tables S10 and S11 and Figs. S7 through S9). Kaplan-Meier curves for death from any cause after premature permanent trial drug discontinuation are provided in Figure S10.

\section{DISCUSSION}

GALILEO was a randomized, controlled trial to evaluate the efficacy and safety of rivaroxabanbased antithrombotic therapy as compared with antiplatelet-based therapy after successful TAVR in patients without an established indication for anticoagulation. A dose of rivaroxaban of $10 \mathrm{mg}$ daily (lower than the approved dose for stroke prevention in patients with atrial fibrillation) was selected to provide a level of anticoagulation to prevent valve surface thromboembolism while mitigating bleeding complications.

We observed that the rivaroxaban group had higher rates of death or thromboembolic complications in the intention-to-treat analysis (rates that were attenuated in the on-treatment analysis) and higher rates of bleeding complications. These results underscore the challenge of antithrombotic therapy in the TAVR population, which includes patients who are generally elderly, potentially frail, or affected by multiple coexisting conditions associated with an increased risk of both bleeding and thromboembolic events. The lack of a clinical benefit of rivaroxaban in this context occurred despite evidence from an imaging substudy of GALILEO (also now published in the Journal) ${ }^{21}$ that rivaroxaban was associated with a lower incidence of subclinical valve-leaflet thickening and reduced leaflet motion than antiplatelet therapy. 


\begin{tabular}{|c|c|c|c|c|c|c|}
\hline \multirow[t]{2}{*}{ Outcome } & \multicolumn{2}{|c|}{$\begin{array}{l}\text { Rivaroxaban Group } \\
(\mathrm{N}=826)\end{array}$} & \multicolumn{2}{|c|}{$\begin{array}{l}\text { Antiplatelet Group } \\
\qquad(\mathrm{N}=818)\end{array}$} & \multirow{2}{*}{$\begin{array}{c}\text { Difference } \\
(95 \% \mathrm{CI}) \\
\text { incidence rate/ } \\
100 \text { person- } y r\end{array}$} & \multirow[t]{2}{*}{$\begin{array}{l}\text { Hazard Ratio } \\
(95 \% \mathrm{Cl})\end{array}$} \\
\hline & no. (\%) & $\begin{array}{l}\text { incidence rate/ } \\
100 \text { person- } y r\end{array}$ & no. (\%) & $\begin{array}{l}\text { incidence rate/ } \\
100 \text { person- } y r\end{array}$ & & \\
\hline \multicolumn{7}{|l|}{ Efficacy outcomes } \\
\hline Primary efficacy outcome $†$ & $105(12.7)$ & 9.8 & $78(9.5)$ & 7.2 & $2.6(0.1$ to 5.1$)$ & 1.35 (1.01 to 1.81$)$ \\
\hline Death & $64(7.7)$ & 5.8 & $38(4.6)$ & 3.4 & $2.4(0.6$ to 4.1$)$ & 1.69 (1.13 to 2.53$)$ \\
\hline From cardiovascular causes & $35(4.2)$ & 3.2 & $27(3.3)$ & 2.4 & $0.7(-0.7$ to 2.1$)$ & 1.30 (0.79 to 2.14$)$ \\
\hline From noncardiovascular causes & $29(3.5)$ & 2.6 & $11(1.3)$ & 1.0 & $1.6(0.5$ to 2.7$)$ & 2.67 (1.33 to 5.35$)$ \\
\hline Stroke & $30(3.6)$ & 2.8 & $25(3.1)$ & 2.3 & $0.5(-0.8$ to 1.8$)$ & 1.20 (0.71 to 2.05$)$ \\
\hline Ischemic & $28(3.4)$ & 2.6 & $22(2.7)$ & 2.0 & $0.6(-0.7$ to 1.8$)$ & 1.28 (0.73 to 2.23$)$ \\
\hline Hemorrhagic & $2(0.2)$ & 0.2 & $3(0.4)$ & 0.3 & $-0.1(-0.5$ to 0.3$)$ & $0.67(0.11$ to 3.98$)$ \\
\hline Myocardial infarction & $23(2.8)$ & 2.1 & $17(2.1)$ & 1.5 & 0.6 (-0.6 to 1.7$)$ & 1.37 (0.73 to 2.56$)$ \\
\hline Symptomatic valve thrombosis & $3(0.4)$ & 0.3 & $7(0.9)$ & 0.6 & $-0.4(-0.9$ to 0.2$)$ & $0.43(0.11$ to 1.66$)$ \\
\hline Pulmonary embolism & $3(0.4)$ & 0.3 & $2(0.2)$ & 0.2 & $0.1(-0.3$ to 0.5$)$ & 1.49 (0.25 to 8.93$)$ \\
\hline Deep-vein thrombosis & $1(0.1)$ & 0.1 & $4(0.5)$ & 0.4 & $-0.3(-0.7$ to 0.1$)$ & 0.25 (0.03 to 2.23$)$ \\
\hline Systemic embolism & $1(0.1)$ & 0.1 & $1(0.1)$ & 0.1 & $0.0(-0.3$ to 0.3$)$ & 0.98 (0.06 to 15.69$)$ \\
\hline Key secondary efficacy outcome & $83(10.0)$ & 7.8 & $68(8.3)$ & 6.3 & $1.5(-0.8$ to 3.7$)$ & 1.22 (0.89 to 1.69$)$ \\
\hline Net clinical benefit $\llbracket$ & $137(16.6)$ & 13.2 & $100(12.2)$ & 9.4 & 3.8 (0.9 to 6.7$)$ & 1.39 (1.08 to 1.80$)$ \\
\hline \multicolumn{7}{|l|}{ Safety outcomes } \\
\hline Primary safety outcomeq & $46(5.6)$ & 4.3 & $31(3.8)$ & 2.8 & $1.5(-0.1$ to 3.1$)$ & 1.50 (0.95 to 2.37$)$ \\
\hline $\begin{array}{l}\text { VARC life-threatening or disabling } \\
\text { bleeding }\end{array}$ & $18(2.2)$ & 1.6 & $17(2.1)$ & 1.5 & 0.1 (-1.0 to 1.2$)$ & 1.06 (0.55 to 2.06$)$ \\
\hline Fatal bleeding & $2(0.2)$ & 0.2 & $1(0.1)$ & 0.1 & $0.1(-0.2$ to 0.4$)$ & 2.01 (0.18 to 22.19$)$ \\
\hline VARC major bleeding & $30(3.6)$ & 2.8 & $15(1.8)$ & 1.4 & $1.4(0.2$ to 2.6$)$ & 2.02 (1.09 to 3.76$)$ \\
\hline TIMI major or minor bleeding & $42(5.1)$ & 3.9 & $24(2.9)$ & 2.2 & 1.7 (0.3 to 3.2$)$ & 1.78 (1.08 to 2.94$)$ \\
\hline ISTH major bleeding & $49(5.9)$ & 4.6 & $30(3.7)$ & 2.7 & $1.9(0.2$ to 3.5$)$ & 1.66 (1.05 to 2.62 ) \\
\hline BARC type 2,3 , or 5 bleeding & 148 (17.9) & 15.4 & $85(10.4)$ & 8.2 & $7.2(4.2$ to 10.3$)$ & 1.84 (1.41 to 2.41$)$ \\
\hline
\end{tabular}

* The $95 \%$ confidence intervals (Cls) were not adjusted for multiple comparisons. The proportionality assumption for the primary efficacy and safety outcomes was not violated. BARC denotes Bleeding Academic Research Consortium, ISTH International Society on Thrombosis and Hemostasis, TIMI Thrombolysis in Myocardial Infarction, and VARC Valve Academic Research Consortium.

$\dagger$ The primary efficacy outcome was defined as the composite of death, stroke, myocardial infarction, symptomatic valve thrombosis, pulmonary embolism, deep-vein thrombosis, or systemic embolism.

$¥$ The key secondary efficacy outcome was defined as the composite of death from cardiovascular causes, stroke, myocardial infarction, symptomatic valve thrombosis, pulmonary embolism, deep-vein thrombosis, or systemic embolism.

$\int$ Net clinical benefit was defined as the composite of the primary efficacy and primary safety outcomes.

q The primary safety outcome was defined as the composite of VARC life-threatening, disabling, or major bleeding.

The overall event rates in this trial were lower than anticipated, probably reflecting the prerequisite of a successfully completed procedure and the overall declining risk profile among patients referred for TAVR (because of expanding indications). However, the rates are in line with those in the pivotal trials involving low-risk and intermediate-risk populations. ${ }^{6,7}$ Although the routine use of higher-dose rivaroxaban (15 to $20 \mathrm{mg}$ daily) in this trial population would have been expected to increase bleeding complications, we do not know whether a lower dose (e.g., $2.5 \mathrm{mg}$ twice daily) might have afforded an improved risk-benefit profile as compared with the present results.

The higher number of deaths in the rivaroxaban group than in the antiplatelet group did not appear to be directly attributable to the higher 
risk of bleeding in the rivaroxaban group. Among patients assigned to rivaroxaban who died, only a minority had a major bleeding event, myocardial infarction, or stroke within 30 days before death, and most deaths occurred long after discontinuation of the trial drug. Most of the adjudicated causes of death in the rivaroxaban group were sudden or from unknown reasons, as well as due to noncardiovascular causes. Hence, the mechanism underlying the higher mortality in the rivaroxaban group observed in the intentionto-treat analysis in this trial is unclear. The between-group differences in mortality were attenuated in the on-treatment analysis.

Since the inception of TAVR, postprocedural antithrombotic therapy has been based on expert consensus according to regimens used in the pivotal trials. ${ }^{14,15,22-24}$ Recent registry results have indicated an association between oral anticoagulation at hospital discharge and an increased risk of death but a decreased risk of bioprosthetic valve dysfunction in comparison to patients undergoing TAVR who did not receive anticoagulation therapy. ${ }^{25}$ Whether a short-term course of anticoagulation monotherapy after TAVR is safe and effective warrants further investigation. The 90-day landmark analyses that we conducted did not suggest consistent differential effects over time.

GALILEO was an open-label trial and was potentially subject to reporting and ascertainment bias. However, trial outcomes were prespecified with the use of standardized definitions and adjudicated by a clinical-events committee whose members were unaware of the trial-group assignments. Patients undergoing TAVR with an established indication for anticoagulation were not included in this trial, and treatment strategies for this patient population are being investigated in ongoing studies (ClinicalTrials.gov numbers, NCT02247128, NCT02664649, NCT02943785, and NCT02735902). On-treatment analyses are generally subject to misinterpretation since they effectively subvert the randomization, because patients who continue to receive treatment differ from those who do not, and thus their subsequent risk of an event is no longer comparable between the trial groups. In the present trial, in which there was a substantial imbalance in treatment discontinuation, the on-treatment analysis may be biased as described above. The $P$ values in this article must be read with prudence, because these tests were not prespecified.
Because we report multiple confidence intervals in the context of a trial that was prematurely terminated, all estimated treatment effects and their confidence intervals should be interpreted with caution. Finally, the early trial termination constitutes a limitation in its own right.

Among patients without an established indication for anticoagulation after successful TAVR, a treatment strategy including anticoagulation with rivaroxaban at a dose of $10 \mathrm{mg}$ daily was associated with a higher risk of death or thromboembolic complications and a higher risk of bleeding than an antiplatelet-based strategy.

Supported by Bayer in collaboration with Janssen Pharmaceuticals.

Dr. Dangas reports receiving lecture fees from Bayer, receiving grant support, paid to his institution, and lecture fees from Daiichi Sankyo, and previously holding equity in Medtronic; Dr. Möllmann, receiving lecture fees from AstraZeneca, Bayer, Boehringer Ingelheim, Bristol-Myers Squibb, Daiichi Sankyo, and Pfizer; Dr. Makkar, receiving grant support, consulting fees, and travel support from Abbott Vascular, grant support, lecture fees, and travel support from Edwards Lifesciences, and grant support and consulting fees from Medtronic and Boston Scientific; Dr. Herrmann, receiving grant support, paid to his institution, from Abbott Vascular and Boston Scientific and grant support, paid to his institution, and consulting fees from Edwards Lifesciences and Medtronic; Dr. Giustino, receiving consulting fees from Bristol-Myers Squibb/Pfizer; Dr. De Backer, receiving lecture fees from Boston Scientific; Dr. Guimarães, being employed by Cardialysis; Dr. Mack, serving as a trial coprimary investigator for Edwards Lifesciences and Abbott Vascular and serving as a study chair for Medtronic; Dr. Schäfer, receiving grant support from the Medicines Company; Dr. Thomitzek, being employed by and holding stock in Bayer; Dr. Valgimigli, receiving lecture fees from AstraZeneca, Alvimedical CID, Vifor Pharma, and Medscape, grant support and lecture fees from Terumo, consulting fees and lecture fees from Abbott Vascular, Bayer, and Bristol-Myers Squibb, and consulting fees from Daiichi Sankyo, Opsens, CoreFLOW, Idorsia Pharmaceuticals, and iVascular; Dr. Vranckx, receiving fees for serving on a speakers bureau from Daiichi Sankyo, lecture fees from AstraZeneca, and fees for serving on a steering committee and travel support from CSL Behring; Dr. Welsh, receiving grant support and honoraria from AstraZeneca, Bayer, and Boehringer Ingelheim; Dr. Wildgoose, being employed by and holding stock in Janssen Pharmaceuticals; Dr. Volkl, being employed by Janssen Pharmaceuticals; Dr. van Amsterdam, being employed by Cardialysis; Dr. Zazula, being employed by Bayer; Dr. Mehran, receiving advisory board fees and consulting fees from Sanofi-Aventis and Janssen, receiving lecture fees from Bayer, receiving grant support, paid to her institution, and lecture fees from Daiichi Sankyo, and previously holding equity in Medtronic; and Dr. Windecker, receiving grant support, paid to his institution, advisory board fees, and travel support from Amgen and grant support, paid to his institution, from Abbott Vascular, Bayer, Bristol-Myers Squibb, CSL Behring, Boston Scientific, Biotronik, Medtronic, Edwards Lifesciences, Polares Medical, and Sinomed. No other potential conflict of interest relevant to this article was reported.

Disclosure forms provided by the authors are available with the full text of this article at NEJM.org.

A data sharing statement provided by the authors is available with the full text of this article at NEJM.org. 
APPENDIX

The authors' full names and academic degrees are as follows: George D. Dangas, M.D., Ph.D., Jan G.P. Tijssen, Ph.D., Jochen Wöhrle, M.D., Lars Sфndergaard, M.D., Martine Gilard, M.D., Helge Möllmann, M.D., Raj R. Makkar, M.D., Howard C. Herrmann, M.D., Gennaro Giustino, M.D., Stephan Baldus, M.D., Ole De Backer, M.D., Ph.D., Ana H.C. Guimarães, Ph.D., Lars Gullestad, M.D., Annapoorna Kini, M.D., Dirk von Lewinski, M.D., Michael Mack, M.D., Raúl Moreno, M.D., Ulrich Schäfer, M.D., Julia Seeger, M.D., Didier Tchétché, M.D., Karen Thomitzek, M.D., Marco Valgimigli, M.D., Ph.D., Pascal Vranckx, M.D., Ph.D., Robert C. Welsh, M.D., Peter Wildgoose, Ph.D., Albert A. Volkl, Pharm.D., Ana Zazula, M.D., Ronald G.M. van Amsterdam, Ph.D., Dip.Phar.Med., Roxana Mehran, M.D., and Stephan Windecker, M.D.

The authors' affiliations are as follows: the Zena and Michael A. Wiener Cardiovascular Institute, Icahn School of Medicine at Mount Sinai, New York (G.D.D., G.G., A.K., R. Mehran); National and Kapodistrian University of Athens, Athens (G.D.D.); Amsterdam University Medical Centers-University of Amsterdam, Amsterdam (J.G.P.T.), and Cardialysis, Academic Research Organization, Rotterdam (J.G.P.T., A.H.C.G., R.G.M.A.) — both in the Netherlands; the Department of Internal Medicine II, University of Ulm, Ulm (J.W., J.S.), the Department of Internal Medicine I, St. Johannes Hospital Dortmund, Dortmund (H.M.), the Department of Internal Medicine III, Heart Center, University Hospital of Cologne, Cologne (S.B.), the Department of General and Interventional Cardiology, University Hospital Hamburg-Eppendorf, Hamburg (U.S.), and Bayer, Berlin (K.T.) - all in Germany; the Heart Center, Rigshospitalet, University of Copenhagen, Copenhagen (L.S., O.D.B.); La Cavale Blanche University Hospital, Cardiology Department, Brest (M.G.), and Clinique Pasteur, Toulouse (D.T.) - both in France; Smidt Heart Institute, Cedars-Sinai Medical Center, Los Angeles (R.R.M.); the University of Pennsylvania, Philadelphia (H.C.H.); the Department of Cardiology, Oslo University Hospital Rikshospitalet, and the Institute of Clinical Medicine, University of Oslo - all in Oslo (L.G.); the Department of Cardiology, Medical University of Graz, Graz, Austria (D.L.); Baylor Scott and White Health, Temple, TX (M.M.); the Department of Cardiology, University Hospital of La Paz, Hospital La Paz Institute for Health Research, Madrid (R. Moreno); the Department of Cardiology, Inselspital, Bern University Hospital, University of Bern, Bern, Switzerland (M.V., S.W.); the Department of Cardiology and Critical Care Medicine, Hartcentrum Hasselt, and Faculty of Medicine and Life Sciences, University of Hasselt - all in Hasselt, Belgium (P.V.); Mazankowski Alberta Heart Institute, University of Alberta, Edmonton, Canada (R.C.W.); Janssen Pharmaceuticals, Titusville, NJ (P.W., A.A.V.); and Bayer, São Paulo (A.Z.).

REFERENCES

1. Smith CR, Leon MB, Mack MJ, et al. Transcatheter versus surgical aortic-valve replacement in high-risk patients. N Engl J Med 2011;364:2187-98.

2. Leon MB, Smith CR, Mack MJ, et al. Transcatheter or surgical aortic-valve replacement in intermediate-risk patients. N Engl J Med 2016;374:1609-20.

3. Leon MB, Smith CR, Mack M, et al Transcatheter aortic-valve implantation for aortic stenosis in patients who cannot undergo surgery. N Engl J Med 2010;363: 1597-607.

4. Reardon MJ, Van Mieghem NM, Popma JJ, et al. Surgical or transcatheter aorticvalve replacement in intermediate-risk patients. N Engl J Med 2017;376:1321-31. 5. Adams DH, Popma JJ, Reardon MJ, et al. Transcatheter aortic-valve replacement with a self-expanding prosthesis. N Engl J Med 2014;370:1790-8.

6. Mack MJ, Leon MB, Thourani VH, et al. Transcatheter aortic-valve replacement with a balloon-expandable valve in low-risk patients. N Engl J Med 2019;380:1695-705.

7. Popma JJ, Deeb GM, Yakubov SJ, et al. Transcatheter aortic-valve replacement with a self-expanding valve in low-risk patients. N Engl J Med 2019;380:1706-15.

8. Hansson NC, Grove EL, Andersen HR, et al. Transcatheter aortic valve thrombosis: incidence, predisposing factors, and clinical implications. J Am Coll Cardiol 2016;68:2059-69.

9. Chakravarty T, Sфndergaard L, Friedman J, et al. Subclinical leaflet thrombosis in surgical and transcatheter bioprosthetic aortic valves: an observational study. Lancet 2017;389:2383-92.
10. Makkar RR, Fontana G, Jilaihawi H, et al. Possible subclinical leaflet thrombosis in bioprosthetic aortic valves. N Engl J Med 2015;373:2015-24.

11. Puri R, Auffret V, Rodés-Cabau J. Bioprosthetic valve thrombosis. J Am Coll Cardiol 2017;69:2193-211.

12. Dangas GD, Weitz JI, Giustino G, Makkar R, Mehran R. Prosthetic heart valve thrombosis. J Am Coll Cardiol 2016; 68:2670-89.

13. Jose J, Sulimov DS, El-Mawardy M, et al. Clinical bioprosthetic heart valve thrombosis after transcatheter aortic valve replacement: incidence, characteristics, and treatment outcomes. JACC Cardiovasc Interv 2017;10:686-97.

14. Baumgartner $\mathrm{H}$, Falk V, Bax JJ, et al. 2017 ESC/EACTS guidelines for the management of valvular heart disease. Eur Heart J 2017;38:2739-91.

15. Nishimura RA, Otto CM, Bonow RO, et al. 2014 AHA/ACC guideline for the management of patients with valvular heart disease: a report of the American College of Cardiology/American Heart Association Task Force on Practice Guidelines. J Am Coll Cardiol 2014;63(22):e57e185.

16. Patel MR, Mahaffey KW, Garg J, et al. Rivaroxaban versus warfarin in nonvalvular atrial fibrillation. N Engl J Med 2011; 365:883-91.

17. Mega JL, Braunwald E, Wiviott SD, et al. Rivaroxaban in patients with a recent acute coronary syndrome. N Engl J Med 2012;366:9-19.

18. Eikelboom JW, Connolly SJ, Bosch J, et al. Rivaroxaban with or without aspirin in stable cardiovascular disease. $\mathrm{N}$ Engl J Med 2017;377:1319-30.

19. Windecker S, Tijssen J, Giustino G, et al. Trial design: rivaroxaban for the prevention of major cardiovascular events after transcatheter aortic valve replacement: rationale and design of the GALILEO study. Am Heart J 2017;184: 81-7.

20. Kappetein AP, Head SJ, Généreux P, et al. Updated standardized endpoint definitions for transcatheter aortic valve implantation: the Valve Academic Research Consortium-2 consensus document. J Am Coll Cardiol 2012;60:1438-54.

21. De Backer O, Dangas GD, Jilaihawi H, et al. Reduced leaflet motion after transcatheter aortic-valve replacement. N Engl J Med 2020;382:130-9.

22. Van Belle E, Hengstenberg C, Lefevre $\mathrm{T}$, et al. Cerebral embolism during transcatheter aortic valve replacement: the BRAVO-3 MRI study. J Am Coll Cardiol 2016;68:589-99.

23. Dangas GD, Lefèvre T, Kupatt C, et al. Bivalirudin versus heparin anticoagulation in transcatheter aortic valve replacement: the randomized BRAVO-3 trial. J Am Coll Cardiol 2015;66:2860-8.

24. Dangas GD, Giustino G. Art and science of cerebrovascular event prevention after transcatheter aortic valve replacement. Circ Cardiovasc Interv 2016;9:9.

25. Overtchouk P, Guedeney P, Rouanet S, et al. Long-term mortality and early valve dysfunction according to anticoagulation use: the FRANCE TAVI registry. J Am Coll Cardiol 2019;73:13-21.

Copyright (C) 2019 Massachusetts Medical Society. 